\title{
What Teachers Want: Elementary Teachers' Perceptions of STEM-focused Professional Development
}

\author{
Jennifer Galindo ${ }^{1}$ Sunddip Panesar Aguilar ${ }^{2 *}$ \\ 1. School Principal, American College of Education, Florida, USA \\ 2. School of Rehabilitative Sciences, University of St. Augustine, St. Augustine, Florida, USA \\ * E-mail of the corresponding author: saguilar@usa.edu
}

\begin{abstract}
With a recent increased focus on science, technology, engineering, and math (STEM) education nationally, more elementary schools are embarking on this path. However, the problem is that elementary teachers who provide STEM instruction require a level of professional development which may not be currently offered, which may shape the teacher's self-efficacy and how the teacher perceives his or her role in STEM implementation. Professional development offerings need to be designed to adequately provide elementary teachers with the learning needed to be confident and successful at implementing integrated STEM education. The purpose of the qualitative instrumental case study was to explore the experiences of fifth-grade science teachers in a large urban school district in Florida regarding STEM-focused professional development and the perceived impact of these experiences on teacher self-efficacy in implementing integrated STEM education in the classroom. Using semistructured interviews, reflective notes, and surveys, 14 current elementary teachers were interviewed regarding experiences with STEM professional development and how those experiences shaped self-efficacy in effectively implementing integrated STEM education. The study revealed the participating teachers had limited STEM professional development experiences, with the majority being self-directed. The study also revealed participating teachers felt increased creativity is necessary for successful STEM implementation. Additionally, the participants desired a personalized professional development approach combined with coaching and mentoring opportunities around STEM.
\end{abstract}

Keywords: STEM instruction, professional development, self-efficacy, elementary STEM instruction, STEM professional development.

DOI: $10.7176 / \mathrm{JEP} / 10-21-14$

Publication date:July $31^{\text {st }} 2019$

\section{Introduction}

The essence of education is to guide students toward successful future outcomes. Considering $85 \%$ of the career fields which will be available to today's elementary students have yet to exist, educators constantly inquire as to how to prepare students for a future in an unknown career field requiring an unknown skill set while focusing on the necessary skills needed for academic success today (Berland, 2014; Capraro \& Han, 2014; National Science Foundation [NSF], 2013; Vasquez, 2015). Educators employ a variety of approaches to address the needs of today's students for the work of tomorrow. One such approach places an emphasis on science, technology, engineering, and mathematics (STEM) education integrated throughout the current curriculum (Capraro \& Han, 2014; Nadelson, Seifert, Moll, \& Coats, 2013). The need to embed 21st-century skills of creativity, communication, critical thinking, and collaboration into learning has also found its way into STEM curricula.

STEM is derived from the global demand for not only the content skills found in the acronym but also the embedded 21st-century skills of creativity, communication, critical thinking, and collaboration (United States [U.S.] Department of Education [USDoE], 2016; Vasquez, 2015). The USDoE (2016) predicted STEM jobs will increase almost $14 \%$ by 2020 and anticipate a dramatic increase in the biomedical fields; however, the same report noted levels as low as $16 \%$ of high school seniors demonstrate proficiency in math and express an interest in STEM careers.

The United States is falling behind internationally, ranking 29th in math and 22nd in science among industrialized nations (USDoE, 2016). STEM-integrated curriculum focuses on student-centered problem-solving approaches woven throughout the learning process (Jones, 2014; Kennedy \& Odell, 2014). STEM education consists of a continuum of rigorous curriculum, instruction, and assessment to ensure the core qualities of STEM are preserved (Kennedy \& Odell, 2014). 
Despite advances in technology and virtual education, the foundation of learning still lies in the art and science of teaching. A teacher's greatest impact on student learning comes when the educator has the tools and understanding to meet the learning needs of the students (Vasquez, 2015). Considering the relative novelty of STEM education and the variety of components associated with the meta-disciplinary approach to learning, teachers are often left feeling underprepared and self-conscious about personal effectiveness in this field, essentially impacting student learning (NSF, 2013; Vasquez, 2015). Professional development opportunities in STEM serve to bridge the gap between current elementary teacher skill sets and the skills required for successful STEM implementation (Vasquez, 2015).

Although school systems nationally are developing STEM course offerings for students at the secondary level, little change can be seen at the elementary level. Much of STEM professional development in general is relegated to school districts and seen as an add-on for when time permits (Smith, Rayfield, \& McKim, 2015). The lack of emphasis on STEM content in elementary teacher preparation programs leads to teachers at the elementary level lacking the content background necessary to support students through STEM lessons. To successfully build selfefficacy in STEM, teachers need to be encouraged to foster the same sense of wonder and exploration held by elementary students (Kennedy \& Odell, 2014).

For STEM integration to successfully be implemented, it is imperative teachers be provided ample opportunities to engage in STEM experiences personally. Many of the experiences currently occurring come in the form of externships, collegiate courses, and work-study programs (Wells, 2013). However, most of these opportunities are provided to teachers at the high school level and beyond. Corporations such as Discovery Education (2017) are at the forefront of working with school districts, school leaders, and teachers nationally to increase the prevalence of STEM instruction in schools. Discovery Education offers curriculum ideas, professional development, and learning resources focused on STEM. However, according to the Discovery Education (2017) success stories, partnerships have been forged with 23 counties in only 11 states.

As schools and districts embark on STEM instruction, the need for STEM-focused professional development for teachers arises. STEM instruction did not become prevalent in most teacher preparation programs until 2010 (Capraro \& Han, 2014). The lack of STEM education in teacher preparation programs amplifies the need for professional development for millions of teachers whose only experience with STEM instruction has come from district professional development offerings or self-exploration. Therefore, the need for a study of this nature serves to develop a foundation for the establishment of quality professional development in STEM at the elementary level building both teacher capacity and self-efficacy in this field.

\section{Literature Review}

The problem explored in this research is that elementary teachers who provide STEM instruction require a level of professional development which may not be currently offered by the school or district. This lack of professional development may shape how the teacher perceives the teacher's role in implementing STEM education. The purpose of the qualitative instrumental case study was to explore the experiences of fifth-grade science teachers in a large urban school district in Florida regarding STEM-focused professional development and the perceived impact of these experiences on teacher self-efficacy in implementing integrated STEM education in the classroom.

In establishing the parameters for this study, an extensive review of literature was completed surrounding several key ideas and concepts. Searches for published research and journals were made in ERIC, JSTOR, and National Science Teacher Association-related journals. The literature review consisted of searches for STEM in the classroom. Searches also expanded into the topics of professional development in STEM and professional development for teachers in general. A total of 38 sources were used as part of the literature review. A recurring theme of self-efficacy was found in the literature on professional development, which led to further searches on teacher self-efficacy in STEM as well as ways to develop self-efficacy.

\section{Professional Development in STEM}

The STEM integration approach expects STEM content to interact meaningfully with literacy while focusing on interactivity, cooperative learning, cognitive development, and social skills (Nadelson et al., 2013). The power of integrating STEM throughout the entire curriculum comes in its accessibility to at-risk and low-achieving students. In many cases, these populations are excluded from stand-alone STEM courses and therefore not provided access to the skills and knowledge base needed for success in careers requiring these skills. The integration of STEM throughout the curriculum provides this population the access and support needed to break the cycle of poverty currently being faced (Nadelson et al., 2013). The integrated nature of STEM requires teachers to engage in specialized professional development.

In this era of high-stakes accountability, strategic professional development is critical to the success of education 
(Gulamhussein, 2013; Nadelson et al., 2013). In her 2013 report on effective professional development for the Center for Public Education, Gulamhussein asserted the current method of the one-time workshop assumes the only development need of teachers lies in the arena of content. Through her research, Gulamhussein determined five guiding principles for effective professional development: significant and ongoing time for professional development, teacher support during implementation, active engagement of the teacher in the initial exposure to a concept, modeling of expected implementation, and specific to the discipline or grade level. With these principles in mind, reviewing current literature surrounding STEM professional development for teachers allowed the interview questions established for the study to explore the experiences teachers have either had or seek when engaging in current STEM training opportunities.

Nadelson et al. (2013) conducted a study detailing teacher involvement and impact in an i-STEM summer institute. The i-STEM project served as a connecting force between business, government, and education in the effort to extend STEM education (Nadelson et al., 2013). Through the i-STEM project, the researchers assessed the impact this collaborative professional development summer institute had on teacher comfort and perceptions of STEM. Although the institute was open to all grade levels (K-12), most of the participants taught Grades 5-9. Results revealed positive correlations between content knowledge development and teacher perceptions of STEM. Additionally, a negative relationship between levels of pedagogical discontentment and efficacy was found. Essentially, the more confident the teachers became in STEM, the less stressful the pedagogical shift was to make (Nadelson et al., 2013). It is important to note the summer institute attended by these participants addressed a specific professional development need for STEM teachers; it combined both content and pedagogy for an extended time. All five guiding principles for effective professional development set out by Gulamhussein (2013) were met during this institute.

As professional development in STEM is defined, studies consistently demonstrate a need to address both the content and delivery of STEM education. Nadelson and Seifert (2013) explained the idea of STEM as a static body of knowledge which can be delivered in prescribed processes presents a conceptual hurdle which is essential to address. STEM professional development needs vary as greatly as STEM instructional approaches. A working definition of place-based STEM was established by Nadelson and Seifert (2013) in a study on perceptions, engagement, and practices of teachers seeking STEM professional development. Place-based STEM incorporates the leveraging of opportunities, structures, and features of the school community to ensure learning is contextual and rooted in meaning (Nadelson \& Seifert, 2013).

Keeping the goal of place-based STEM in mind, a STEM continuum was established with the far left consisting of STEM separated into distinct disciplines and the far right consisting of full integration of STEM (Nadelson \& Seifert, 2013). STEM education routinely falls across this continuum. Nadelson and Seifert (2013) administered several surveys to 377 teachers who attended STEM professional development provided by the researchers. Results supported the belief the more teachers participated in a variety of STEM professional development opportunities, the more comfortable the teachers were in implementing place-based STEM.

With the integration of STEM across curricula, student achievement in those fields is anticipated to increase. However, the dramatic increase in interest in STEM careers and content has not translated into a dramatic increase in student achievement. Oner and Capraro (2016) supported the theory stating insufficient professional development of teachers is a possible effect limiting the impact on student achievement. In a study on STEM academies and the impact on student achievement, Oner and Capraro compared the mathematics and science scores of students in STEM academies to those not in STEM-designated academies. The researchers found the designation of an academy had no bearing on student achievement; rather, achievement was impacted more by teacher preparation and professional development than course designation.

Schools which encompassed an academy provided the entire staff twice as much professional development in STEM-related content than did the non-STEM counterparts (Oner \& Capraro, 2016). Oner and Capraro (2016) asserted this component leads to a difference in achievement scores. The researchers made this conclusion because although there were significant achievement differences between students in STEM academy schools and nonSTEM schools, there was no significant difference between students at the STEM academy school who were not enrolled in the academy but were in the same school. The aforementioned studies share the important role professional development plays in building a rich STEM program.

\section{STEM in the Elementary Setting}

Many of the studies on elementary STEM programs involve magnet program offerings or additional supplementary program offerings such as after-school programs and class add-ons (Kennedy \& Odell, 2014; Nadelson et al., 2013; Oner \& Capraro, 2016). When reviewing the literature, limited work in this arena was found. The reviewed studies all share the sentiment elementary school centers emphasize literacy and math as core content areas, relegating 
content areas such as science and social studies to if-time-permits status. Therefore, the teachers also consider these content areas as optional (Oner \& Capraro, 2016).

The schools that are breaking the optional STEM approach do so with limited support from districts. Lehman, Kim and Harris (2014) conducted a mixed-methods study examining the collaboration between university STEM faculty and elementary teachers embarking on an engineering, design-based program entitled Science Learning through Engineering Design. The participants working on curriculum design were developing products intended for use in Grades 3 and 4, while the participants involved in product implementation were utilizing lessons designed previously and intended for use with fifth- and sixth-grade students. Throughout the study, teachers cited the greatest success in both design and implementation processes came from the support of the university faculty. Lehman et al. established the need for elementary teachers to receive quality STEM professional development to be successful. Teacher interview responses highlighted the belief that the current school and educational system did not contain the needed academic resources to support the teachers in this shift. It was through collaboration that the teacher's understanding of STEM became deep enough to impact classroom instruction.

Sikma and Osborne (2014) approached STEM at the elementary level in a different arena. The researchers analyzed the process a small school in the Midwest went through when developing its STEM magnet program. As a diverse setting to begin with, the needs of the students and focus of the teachers had traditionally revolved around highstakes accountability. The development of the magnet program had to bridge the divide between the current education economy and the magnet's requirement to be STEM focused. The staff struggled with defining STEM focused as well as how to implement the transition when teachers were not sure of what it even meant to be STEM focused.

Many teacher preparation programs primarily address literacy instructional methods as the main focus rather than content, which leaves new teachers feeling underprepared to address this shift (Elkund, 2015; Sikma \& Osborne, 2014). Teachers at the elementary level lack the content background necessary to support students through STEM lessons. Discomfort with content can lead teachers to be apprehensive about embarking on STEM integration (Eklund, 2015). Teachers need to be encouraged to foster the same sense of wonder and exploration elementary students have. However, to accomplish this sense of wonder, teachers must be prepared and confident in the ability to tackle the content at hand (Lehman et al., 2014).

Conceptual Framework

Self-efficacy is a combination of an individual's capacity, achievements, and motivations (Bandura, 1997). A teacher's self-efficacy has been tied to impact on teaching style, classroom behavior, and development of attitudes toward teaching and new ideas. Teacher self-efficacy has also been tied to impact on student self-efficacy (Elkund, 2015). Teachers who claim to be good at teaching a certain subject tend to yield more confident student results (Bandura, 1997; Elkund, 2015).

In developing his theoretical framework on self-efficacy, Bandura (1997) determined self-efficacy is built in any one of four ways: through mastery experiences, social modeling, social persuasion, and observing the states of physiology. Considering self-efficacy is based on a person's mastery experience, vicarious experience, social persuasion, and physiological reaction, teachers must be afforded ample opportunities for professional development in fields such as integrated STEM so the teacher will not be lacking in STEM self-efficacy (Elkund, 2015; Nadelson et al., 2013). Bandura also connected belief in one's own self-efficacy to one's cognitive, motivational, emotional, and decisional functioning. Teachers with high levels of self-efficacy believe the teacher can positively impact the learning of the students. These teachers are also more willing to take risks and try new approaches because of faith in the teacher's abilities (Elkund, 2015).

\section{Statement of the Problem}

The problem is that elementary teachers who provide STEM instruction require a level of professional development which may not be currently offered, which may shape teachers' self-efficacy and how teachers perceive the teacher's role in STEM implementation. The integration of STEM education into the elementary curricular platform has been met with resistance due to a lack of teacher confidence in the STEM fields as well as a lack of an understanding of the role teachers have in the development of these disciplines in the educational lives of students (Nadelson et al., 2013). When examining the credentials of teachers in secondary education, the NSF (2013) determined almost a quarter of middle and high school math or science teachers held degrees in the fields taught. Content-area degree work was not reflected in the credentials of elementary level teachers as almost $90 \%$ of the teachers held general education degrees. The abundance of general education training at the elementary level explains the limited experience in math and science reported by most teachers (NSF, 2013). Therefore, STEMfocused professional development becomes essential if elementary teachers are going to instruct students in these fields. 
The majority of research on STEM integration has focused on the secondary and collegiate levels. A few studies in the development of STEM in elementary education highlight effective teacher support and development (Jones, 2014). Schools across the nation claim to offer STEM education; however, the teacher's lack of preparedness to offer students the instruction needed to be successful in STEM careers calls into question the effectiveness of the programs. As STEM magnet schools and programs arise, the term STEM is being attached to program offerings, and a common language and approach to instruction is needed for the programs to be successful (Nadelson et al., 2013). The unification of STEM integration on a campus can best be achieved with specifically structured and designed professional development.

\section{Purpose of the Study}

The purpose of the qualitative instrumental case study was to explore the experiences of fifth-grade science teachers in a large urban school district in Florida regarding STEM-focused professional development and the perceived impact of these experiences on teacher self-efficacy in implementing integrated STEM education in the classroom. This study was based on the reasonable assumption that limited impactful exposure to STEM instruction in the elementary years might account for a less-than-desirable increase in the number of students pursuing STEM careers despite an increased interest in math and science (Oner \& Capraro, 2016). The exploration of the connection between STEM-focused professional development experiences and teacher perceptions of STEM-integrated instruction assisted in identifying ways to increase STEM integration effectiveness in elementary classrooms and helped to set the stage for research showing a relationship between the study and the number of teachers entering STEM careers.

As elementary schools in the Florida school district implement STEM instruction, teachers are provided a variety of levels of support and professional development. The experience teachers have with STEM-focused professional development may shape the personal confidence in implementing integrated STEM education. Limited or negative experiences with STEM professional development may inhibit the teacher's willingness to embark in effective STEM implementation. Without effective professional development and support, STEM instruction provided by these teachers may not be at the high quality expected in the classroom (Capraro \& Han, 2014). The qualitative research from the study provided administrators, program planners, and teachers alike a glimpse into the lived experiences of fifth-grade science teachers in the Florida school district. Additionally, the study discussed the STEM-focused professional development experiences teachers felt best supported implementing integrated STEM instruction. Current literature demonstrates the connection between effective STEM implementation and specialized professional development primarily at the secondary level.

\section{Research Questions}

The following research questions guided this qualitative instrumental case study:

RQ 1. What are the experiences of fifth-grade science teachers regarding STEM-focused professional development?

RQ 2. How do these experiences affect fifth-grade science teachers' self-efficacy in implementing integrated STEM education?

RQ 3. What types of professional development experiences did fifth-grade science teachers feel best supported implementing integrated STEM education?

\section{Methodology, Sampling, and Results \\ Sampling}

The school district utilized in the study is a large urban school district in Florida, consisting of 102 elementary schools encompassing a variety of programmatic offerings; one such offering is STEM. The school district has 27 elementary schools designated as offering STEM education. It is from this selection of schools the participants were chosen. The STEM schools in the county vary in socioeconomic status, time designated as a STEM school, and school location. The schools chosen to participate included both Title I and non-Title 1 schools, as well as schools with new STEM programs and schools with established STEM programs.

The sample of participants was generated from fifth-grade science teachers at six elementary schools with STEM programs already established in the Florida school district. Three of the schools are designated as Title I schools and three are non-Title I schools. The reasoning behind selecting fifth-grade science teachers from STEM schools was to increase the possibility of teacher experiences with STEM. Due to the schools' focus, teachers at these schools tend to have more experience with STEM instruction and receive additional professional development opportunities in STEM. In the sample population of 16 teachers, half were from schools with STEM designations of three or more years and half were from schools with STEM designations of fewer than three years.

Purposeful sampling was employed in this study to develop a participant group who had experience with STEM 
instruction in some capacity. The technique of critical case sampling was utilized in the collection of data. Critical case sampling in the study was utilized to zero in on the fifth-grade science teachers' perceptions of STEM-focused professional development, how the professional development experiences have shaped the instructional approach, and self-efficacy levels.

\section{Instrumentation}

The research utilized two instruments to gather data for the study: a researcher-designed interview protocol and the T-STEM survey. Interviews are one of six sources of evidence used in case studies. Semi-structured interviews were conducted one-on-one with participants. Case study interviews tend to resemble guided conversations rather than structured queries (Baxter \& Jack, 2008; Creswell, 2018; Yin, 2014). The interview protocol was developed to establish a flow of discussion on the topic of STEM implementation and professional development experiences.

The question stems grew out of and extended the research questions. They were designed to flow like a conversation. The questions were based on the T-STEM survey to gather deeper insight into how self-efficacy played a role in teacher perceptions. Table 1 demonstrates the connection between the interview questions and research questions established for the study.

\section{Data Collection}

Data collection for this study was generated from four sources. The first source consisted of information derived from semi-structured interviews. The second source stemmed from reflective field notes taken at the conclusion of each interview. Participants partook in a self-efficacy survey, which was analyzed against Bandura's (1997) self-efficacy framework as the third source. The final source of data collection came from pre-existing documents outlining STEM professional development offerings provided by the schools and the district.

Fifth-grade science teachers were interviewed regarding experiences with STEM instruction, STEM professional development experiences, and what professional development the teachers seek to positively impact individual perceptions of STEM instruction. When agreeing to participate in the study, each participant selected a time and date to be interviewed face-to-face. If a face-to-face interview could not be scheduled or the participant preferred, a phone interview was conducted (Creswell, 2018; Yin, 2014). Participants were asked to complete the T-STEM survey (Friday Institute, 2012) prior to the interview. Participants received the T-STEM survey electronically via Google Surveys, which allowed participants to respond easily and the results to be organized once received. Surveys were not anonymous, but results were coded based on participant pseudonyms.

The interview consisted of eight guiding questions. Follow-up questions were asked to get clarification or elaboration of responses. At the conclusion of the interview, the participant was provided the opportunity to elaborate or clarify answers and make additional statements not covered by the questions. Each participant provided contact information in case further information was needed. Once the interview was completed, reflective field notes were written for the interview. These notes assisted in determining the validity of the responses (Baxter \& Jack, 2008; Creswell, 2018; Yin, 2014).

Once the interview was conducted, the T-STEM survey results were analyzed for the teacher and assigned the teacher a designation of high self-efficacy in STEM, moderate self-efficacy in STEM, or low self-efficacy in STEM. By conducting this analysis after the interview, the propensity of the self-efficacy score to lead to prejudgment about the teacher's experiences was eliminated. All interviews were intended to be conducted with no preconceived notions about the teacher's level of efficacy.

\section{Data Analysis and Findings}

The data analysis process in this research study followed Creswell's (2018) data analysis spiral. Creswell referred to the data analysis process as a spiral because "the researcher engages in the process of moving in analytic circles rather than using a fixed linear approach" (p. 185). The data analysis spiral included a five-step process. The initial step consisted of managing and organizing the data, which included preparing files and units for analysis, ensuring the secure storage of files, and selecting the mode for analysis. Once managing and organizing the data was completed, memos were jotted to find emergent ideas. During this part of the process, the data was continuously revisited. While revisiting the data, notes were taken in the margins regarding any reflective thinking during the process and summarized her field notes. It is important this process was captured as it provided an audit trail which served as documentation of the analysis process.

The next step in the data analysis spiral (Creswell, 2018) was describing and classifying codes into themes. This stage served as the essence of qualitative data analysis. Creswell (2018) recommended beginning with description and building categories out of the narratives. Commonly found words were selected to identify initial codes and 
highlighted the codes in the transcribed text. From there, a list of codes was established and applied to various texts. The codes were documented on colored Post-It notes to ease in the organization of categories. The expanded codes were combined into categories. The established categories were then reduced to general themes. Once themes were established, interpretations were developed and assessed. This was the stage in which meaning was derived from the code and interpreted within the construct of the framework established in the literature. Patterns were established at this juncture as refining theories and correlated to the research questions. The final stage of the data analysis spiral was representing and visualizing the data. The data were captured in both narrative and graphic representations.

Interviews were coded manually to provide consistency in the analysis and development of the codes and themes. Each question looked at a component of self-efficacy and professional development. Therefore, categories of words in the responses were developed. The categories were then expanded or combined with like categories to establish themes (Creswell, 2018; Yin, 2014). In addition to the manual coding process, NVivo was used to assist in confirming common themes in the interviews, for cross-checking codes and further analyze the connections between themes.

Themes were established through interview results regarding teacher perceptions of STEM integration and the supports desired for successful STEM integration. Creswell (2018) described themes as overall sets of information consisting of several codes based on a common idea or concept. Based on the literature surrounding research in STEM integration and teacher professional development, the content analysis was deductive in nature with the pre-established themes of perception of STEM implementation, experience with STEM professional development, and self-efficacy as it pertains to Bandura's (1997) self-efficacy framework. Through topics which arose during the interviews, the themes were defined more specifically, and additional unanticipated themes emerged from the analysis.

An open-coding system was used to determine what codes emerged as the interviews were reviewed. Once patterns in the codes emerged, the themes were developed. The analysis of the data from the T-STEM survey designed by the Friday Institute (2012) explored the level of self-efficacy in the participants. Through the implementation of Bandura's (1997) self-efficacy framework as well as researcher-designed questions for use in the semi-structured interviews, the relationship of STEM teachers' perceptions of the role of professional development and individual self-efficacy was explored. Exploring the multiple data points allowed for triangulation of the data and provided a comprehensive look at the connections between STEM-focused professional development and teacher perceptions of the teacher's role in implementing integrated STEM education. Upon completion of the survey, a comprehensive analysis of the T-STEM survey results determined the self-efficacy ratings of the teachers in the components of STEM education at the elementary level. Participants' T-STEM scores also helped to categorize participants into three general categories of STEM self-efficacy: high STEM self-efficacy, moderate STEM self-efficacy, and low STEM self-efficacy. This categorizing allowed for establishment of connections present only at specific selfefficacy levels.

The self-efficacy framework developed by Bandura (1997) explained four ways in which people develop selfefficacy: through mastery experiences, social modeling, social persuasion, and observing states of physiology. The results of the T-STEM surveys also provided information on the teachers' levels of self-efficacy in STEM. The TSTEM survey utilized a Likert scale essentially ensuring the higher the score, the greater the self-efficacy of the participant.

The scores from highest to lowest overall as well as by level were organized. Basing the cutoffs on T-STEM survey research, scores with an average below 4.0 rank as low self-efficacy and scores above 4.5 rank as high self-efficacy. Participants were grouped for analysis by self-efficacy scores. The combination of both data sets began to describe the professional development experiences which yielded the greatest level of self-efficacy development for the participants.

Data analysis requires organization, time, reflection, and the ability to reduce bias (Creswell, 2018; Yin, 2014). Data were secured and kept confidential in a variety of ways. The schools providing participants were coded as Schools A-F, which allowed the schools' and participant's names to remain confidential. Schools were classified as being low-income (Title I) or high-income (non-Title I) and grouped by number of years the school has been designated as a STEM school. Schools designated as STEM schools for three years or fewer were considered new to STEM and schools designated as STEM schools for four or more years were considered established in STEM. The six schools involved in the study exemplified each possible combination of program. Table 2 provides the school descriptors.

Each participant chose a pseudonym at the time of the interview. The name recorded in the interview was only the pseudonym. After the interview, the e-mail name of each participant in the survey was changed to the pseudonym 
as well, which allowed the survey results and interview to be linked but the participant to remain anonymous. Each interview was recorded, with permission of the participant, and transcribed. Each participant was given the option to review the individual's transcript. None of the participants suggested any changes. Once an interview was transcribed, the analysis process began.

Each participant was ranked as having high, moderate, or low self-efficacy in STEM as determined by the individual T-STEM self-efficacy results. For the purpose of this study, participants scoring an average rating of 4.5 or higher on the T-STEM survey were considered as having high STEM self-efficacy. Participants scoring an average rating of 4.0-4.5 on the T-STEM survey were considered as having moderate STEM self-efficacy. Participants scoring an average rating below 4.0 on the T-STEM survey were considered as having low STEM self-efficacy. These cutoffs were established by reviewing the validity data established by Unfried, Faber, Townsend, and Corn (2015) in the vetting process of the T-STEM survey. In other studies utilizing the survey, the average scores fell in the 4.0-4.5 range with highs at 5.0 and lows at 3.0 (Unfried et al., 2015). Seldom were there responses with an overall average which fell below 3.0, which Unfried et al. considered as outliers. The participants in the present study had self-efficacy ratings from 3.6 to 4.6 .

The first interview was the most difficult to analyze, as no themes had been present to launch coding. Each response was read thoroughly to look for words which stood out or were emphasized. The first interviewee was Sam. Sam spoke at length about the standards and her school's emphasis to adhere to the district's scope and sequence, such as the order and depth with which academic content is taught within a subject area. This topic appeared in every portion of her interview.

The word standards became a code. She also shared about time and resources being a need for her. She had ideas for projects to implement, but the time and resources to implement were not readily available. Therefore, time and resources became codes as well. The following codes emerged from Sam's interview: standards, time, resources, schedules, groups, student-centered, side-by-side coaching, and content.

The interviewees after Sam shared many of the same responses, which allowed common themes to emerge. The themes of standards, materials, time, ideas, PBL, and coaching were found throughout each of the interviews. Table 3 shows the participant descriptors by years of teaching, school, and overall self-efficacy score. The selfefficacy score came from the average of the responses given on the T-STEM survey (Friday Institute, 2012).

When analyzed as a group, the data provided through the T-STEM survey demonstrated a variety of needs among the participants. The 13 questions focused on elementary STEM instruction demonstrated a common trend which was then supported by the interview responses. Table 4 displays the frequency (in percentage) with which participants felt components of STEM instruction are being implemented in the individual's classrooms. These components were determined by the Friday Institute (2012) as part of the T-STEM survey.

Each interview was broken into sections based on the interview question's alignment to the research questions, which allowed for the establishment of themes within the context of the research questions. In several cases, the same code word appeared throughout the interview but supported a different theme based on the context of the response. Therefore, it was essential to code the interviews in sections rather than as a whole (Unfried et al., 2015). The coded words were then listed by section and combined to form categories. The categories then set the basis for the themes.

When looking at current experiences of fifth-grade science teachers regarding STEM-focused professional development, two general themes emerged: self-guided and limited. The participants shared a variety of experiences displaying a minimal focus on STEM-focused professional development. The term university-based training was found in the responses of the six participants with over 10 years of experience. The participants with 10 or fewer years included terms such as literacy-based training, peer work, book study, and self-research.

In the reflective notes, it was indicated that participants struggled greatly with the question about STEM professional development. However, each participant was able to give in-depth descriptions as to how STEM should be taught. Descriptions centered on the same four descriptors: collaboration, creativity, problem solving, and hands-on; as essential components to STEM instruction. This finding aligned closely to research demonstrating the effectiveness of the 21 st-century skills (creativity, communication, collaboration, and critical thinking) in the classroom (Capraro \& Han, 2014). This general alignment of thought led the conclusion that common STEM beliefs had been integrated into the training the participants had experienced, even if not done so explicitly.

When coding the section looking at teacher self-efficacy in STEM, a theme of creativity was established. In this section, categories of needs arose. Participants cited needs for materials, time, ideas, and support to build self- 
efficacy. The participants with the highest self-efficacy mentioned professional communities occurring beyond the school and were established during outside trainings. The codes of materials and time were found in all 14 interviews. Each teacher felt the professional development experiences left feelings of excitement about STEM until the participant returned to the classroom and saw a lack of the time and materials to effectively implement what was learned. The exception to this was Sam, who had spent the year in a professional development opportunity which provided her with extensive workshops on STEM and a STEM coach who monitored her progress with in-class visits, support, and modeling. Sam's experience with the side-by-side coaching led her to feel empowered to integrate STEM in the classroom.

When coding the section related to types of professional development experiences desired, the general theme emerging was personalized. All the participants stated a preference for having people in the classrooms supporting teacher growth as educators, especially in STEM. However, approximately half of the participants felt content focus was the greatest need, whereas the other half of the participants felt presentation and ideas were needed most in professional development. It was noted the teachers with the university program professional development felt less content support was needed. The diversity in needs of the teachers was accompanied by a desire for a customized approach to professional development. All 14 participants felt teachers learned better when the professional development was not a sit-and-get approach but more of a hands-on and experiential approach.

The data gathered through this study led to the development of themes focused on each research question. The themes were based on the common codes among the participants. Because analysis was completed in sections based on the research questions, the resulting themes were grouped by research question as well. Table 5 connects the research questions of the study to the themes derived from the data. The connection between the research questions and themes served to deepen the association between the data and the research questions.

\section{STEM-Focused Professional Development Experiences}

The first research question asked, what are the experiences of fifth-grade science teachers regarding STEMfocused professional development? During the interview process, the responses from the following questions were coded and utilized to develop the themes of self-guided and limited:

- $\quad$ Based on your training, describe what STEM looks like in your classroom.

- Based on your training, what do you think STEM should look like in your classroom?

- What do you need to make that change happen?

- What kind of professional development have you participated in regarding STEM?

When asked about the current state of STEM in individual classrooms, $83.3 \%$ of the participants stated the instruction was rooted in the standards with little deviation — something participants saw as a necessary evil. Frank stated, "As a fifth-grade teacher, you know you are going to be evaluated on how well your class does on the test. So, doing something that isn't on the scope and sequence is not accepted." Sam supported this point: "I'd like to do projects all day with them [students], but I have to follow the scope and sequence from the district. There just isn't enough time for everything." The fear of deviating from the scope and sequence was a common concern of the younger teachers.

Each of the participants had a view of STEM integration being interactive and problem-oriented. However, the solutions to bridging the gap between current practice and best practice were seen as mostly beyond teacher control. Frank, Sam, Audrey, Amy, Brit, Sandy, and Jean felt time and materials were needed to bridge the gap. Sandy and Brit emphasized a feeling of being "trapped" by the lack of time and resources and "didn't know where to turn" for ideas. The concern of participants around meeting the view of STEM instruction while meeting the demands of the standards demonstrated the perception of limited access to professional development. The more seasoned teachers cited experiences with university training programs and corporate STEM internships as go-to resources for STEM. Pam, Mandy, and Mark had attended STEM institutes through several state university programs; each described applying for the programs and attended weeklong institutes on campus where participants learned content and implementation strategies. Mandy explained she would like to see "more collaboration outside the district. I know the district cannot afford these institutes. That is where the universities are so helpful." These three teachers built professional learning communities from the institutes attended over five years ago, and still meet today. These participants saw professional development opportunities as the bridge between STEM now and what it can be.

When discussing current experiences with STEM professional development, the teachers saw it as essential to success. Sandy, Brit, and Frank stated expectations of the school and district to lead the proper professional development needed. Pam, Mandy, Amber, and Mark saw STEM professional development as the individual's responsibility. Amber replied, 
I know that the school and district are not going to necessarily provide me with the professional development I want. So, I go and look for it. I want to always be learning, and I won't let a little legwork stop me.

The other participants identified a desire for more professional development and are actively looking for district and local offering but have yet to seek grander opportunities. In reviewing the reflective notes, it was found that these teachers appear to be unsure where to look beyond the district for information. The participants are not members of outside organizations such as the National Science Teachers of America, where much of this information can be found. $100 \%$ of the teachers looked to professional reading materials for ideas. Additionally, $100 \%$ of the participants cited a lack of professional development opportunities as a barrier to growth as STEM teachers. The focus of participants on seeking personalized professional development experiences outside of district offerings led to the finding of self-guided professional development.

\section{Experience Impacting Self-Efficacy}

The second research question asked, how do these experiences affect fifth-grade science teachers' self-efficacy in implementing integrated STEM education? During the interview process, the responses from the following questions were coded and utilized to develop the theme of creativity:

- What skills or talents do you believe an elementary teacher must have to successfully teach STEM?

- What have you experienced that either helped you develop those skills or prevented you from developing those skills?

Each participant felt creativity was an essential skill for STEM teachers. Whether because of a lack of time or materials or because of the strong emphasis on standards over STEM, all of the teachers felt creativity and "outof-the-box thinking" were essential for STEM teachers, and stated self-efficacy was the key to building creativity. Pam supported this notion when she said,

I'm not creative by nature, but the more confident I became in my STEM teaching abilities, the more I allowed myself to take risks and be creative. There is no way to teach this stuff and everything else unless you get a little creative.

Every participant believed creativity could be taught. The participants cited trying new things, team projects, and hands-on professional development as ways to get teachers to embrace creativity. Sandy explained,

I get nervous when I have to try something new. I feel like if I could practice with a peer first and then bring it to my class, it would be more likely to be successful. I have tried things on my own and failed. I hate failing.

From the interviews and survey, it was clear the teachers with less self-efficacy were struggling with the implementation of STEM in classrooms. Each shared an experience in which the individual had taken a risk with no support and been unsuccessful. Utilizing Bandura's (1997) self-efficacy framework, it would be helpful for the participants with lower self-efficacy to be provided opportunities to experience social modeling/mentoring or given the supports allowing successful implementation a STEM lesson with feedback. This support would build confidence in integrating STEM instruction. Each of the teachers relayed a desire to see how STEM "should be done."

Many of the participants expressed a desire for a support system of STEM education. Participants described the offerings at the individual's schools, but only Pam, Mandy, and Mark discussed the STEM socials provided by the school district's STEM department, and only Lisa, Amy, and Sean cited working with a member of the school district's STEM department. The STEM department provided a list of the STEM-related professional development offered. Most of the district-offered professional development has to be requested by the school principal.

When requested, STEM team members would go to a school or classroom and provide either whole-group training or individual/small-group coaching. These resources were unknown to many of the participants. However, the STEM department offers a social four times a year where teachers can learn more about STEM instruction and professional development opportunities. These socials appear to be a link which would build the STEM community identified by participants to increase creativity and self-efficacy. The ideas expressed by the participants led to a need to build up teachers to be risk takers and creative.

\section{Desired Professional Development}

The third research question asked, what types of professional development experiences do fifth-grade science teachers feel best support implementing integrated STEM education? During the interview process, the responses 
from the following questions were coded and utilized to develop the theme of personalized:

- What kind of professional development opportunities would you like to have regarding STEM?

- What professional development opportunities do you feel would best help teachers to develop the skills or talents you discussed?

Each participant expressed a variety of needs when sharing desired professional development support. Some of the participants felt an emphasis on content was what was needed. Lisa stated she would like to receive training in "an area I'm weaker in, like the human body or space. There are so many terms. I'm not sure how to get it all in, and I can't remember it all," whereas Sandy felt professional development should be more methods based, such as "taking a lesson and show them [teachers] how to make it a STEM-related lesson. No, taking a learning goal and how you can make that a STEM-related activity." Frank, Amy, and Jean felt a combination of content and methods was the best approach. Amy shared, "If you don't know the content, you're not going to create an activity that will teach the right material. If you don't know how to create the activity, you need that."

\section{Conclusions}

The results of this study provide several implications to the current literature around STEM in the elementary setting and STEM professional development offerings. Through this study, it was found that participants experienced a need to provide self-guided STEM professional development through a variety of sources. The experiences described by participants revealed the professional development offerings developed by universities and corporations and outlined in the literature have not made it to all classroom settings at the intended level of implementation. This finding is not surprising considering the breadth of educational needs at even the local district level. However, the participants outlined preferred specific approaches when receiving professional development which would assist in further developing local and state offerings.

The professional development discussed in the literature focused on developing content and methodology through a variety of institutes (Nadelson et al., 2013), beginning in teacher preparation programs (Berland, 2014) and inclusion of outside entities (Elkund, 2015). However, the literature failed to address the effectiveness of mentoring and coaching on professional development and the need for personalization. With the professional development desires expressed by participants and the need for creativity to be fostered in students, the literature is expanded to include additional professional development supports for teachers. To effectively implement STEM, increased teacher self-efficacy is needed, as supported through the work of Jones (2014) and this study. As teachers develop comfort and expertise in STEM, a need for direct professional development support lessens and professional development can become more collaborative and individualized.

As STEM becomes more prevalent in the realm of college and career, it is essential students are provided support and learning throughout and among the disciplines. However, the focus of current $\mathrm{K}-5$ education continues to be rooted in the approaches emphasized in the later part of the 1900s. With the establishment of Common Core Standards, a national movement was launched to align K-12 education with the needs of colleges and careers; launching the birth of the STEM movement in K-12 education (Berland, 2014; Lloyd, 2016; USDoE, 2016).

While the standards and curricular expectations have increased, the instructional approaches have yet to evolve. Teachers are instructing new content with old approaches and wondering why intended results are not being achieved. It is the school's obligation to the students to teach, and it is the teachers' obligation to provide students every opportunity to build the community of learning necessary for success. This obligation requires time, materials, creativity, collaboration, and support in ways teachers are not experiencing. Once empowered and supported to bridge the gap between what is and what can be, teachers will lead students into the future awaiting them.

\section{References}

Bandura, A. (1997). Self-efficacy: The exercise of control. New York, NY: Freeman.

Baxter, P., \& Jack, S. (2008). Qualitative case study methodology: Study design and implementation for novice researchers. The Qualitative Report, 13(5), 44-559. Retrieved from http://nsuworks.nova.edu/tqr/vol13/iss $4 / 2$

Berland, L. (2014). Designing for STEM integration. Journal of Pre-College Engineering Education Research, 3(1), 22-31. doi:10.7771/2157-9288.1078

Capraro, R., \& Han, S. (2014). STEM the education frontier to meet 21 st century challenges. Middle Grades Research Journal, 9(3), 15-18. Retrieved from http://www.infoagepub .com/middle-grades-research-journal

Creswell, J. W. (2018). Research design: Qualitative, quantitative, and mixed methods (5th ed.). Los Angeles, CA: Sage Publishing Inc. 
Discovery Education. (2017). Discovery Education offerings. [Website]. Retrieved from http:// discoveryeducation.com

Elkund, J. (2015). Engaging STEM professionals in K-12 professional development. [Web-based presentation]. Retrieved from https://www.systemsbiology.org/

Friday Institute for Educational Innovation. (2012). Teacher efficacy and attitudes toward STEM surveyElementary teachers. Raleigh, NC: Author.

Gulamhussein, A. (2013). Effective professional development in an era of high stakes accountability. [Web-based presentation]. Retrieved from http://www.centerforpubliceducation.org

Jones, V. (2014). Teaching STEM integrative curriculum. Children's Technology and Engineering, 18(3), 37-39. Retrieved from https://www.iteea.org/Publications/Journals /CTE.aspx

Kennedy, T. J., \& Odell, M. R. (2014). Engaging students in STEM education. Science Education International, 25(24) 6-258. Retrieved from http://www.icaseonline.net /seiweb/

Lehman, J., Kim, W., \& Harris, C. (2014). Collaborations in a community of practice working to integrate engineering design in elementary science education. Journal of STEM Education, 15(3), 21-28. Retrieved from http://www.jstem.org

Nadelson, L. S., \& Seifert, A. (2013). Perceptions, engagement, and practices of teachers seeking professional development in place-based integrated STEM. Teacher Education and Practice, 2(6), 242-265. Retrieved from http://www.iiste.org/Journals/index.php/JEP

Nadelson, L. S., Seifert, A., Moll, A., \& Coats, B. (2013). i-STEM summer institute: An integrated approach to teacher professional development in STEM. Journal of STEM Education, 13(2), 69-83. Retrieved from http://www.jstem.org

National Science Foundation. (2013). STEM smart brief: Preparing and supporting STEM educators. [Website]. Retrieved from http://successfulstemeducation.org/sites /successfulstemeducation.org/files/Preparing\%20Supporting\%20STEM\%20Educators FINAL.pdf

Oner, A. T., \& Capraro, R. M. (2016). Is STEM academy designation synonymous with higher student achievement? Education and Science, 41(185), 1-17. http://dx.doi.org/10.15390 /EB.2016.3397

Sikma, L., \& Osborne, M. (2014). Conflicts in developing an elementary STEM magnet school. Theory into Practice, 53(4), 4-10. doi:10.1080/00405841.2014.862112

Smith, K. L., Rayfield, J., \& McKim, B. R. (2015). Effective practices in STEM integration: Describing teacher perceptions and instructional method use. Journal of Agricultural Education, 5(6), 183-203. http://dx.doi.org/10.5032/jae.2015.04183

Stake, R. E. (2000). The art of case study research: Perspectives on practice (2nd ed.). Thousand Oaks, CA: Sage.

Unfried, A., Faber, M., Townsend, L., \& Corn, J. (2015). Validated student, teacher, and principal survey instruments for STEM education programs. Journal of Psychoeducational Assessment, 33(7), 622-639. doi: $10.1177 / 0734282915571160$

U.S. Department of Education. (2016). STEM. [Website]. Retrieved from https://www.ed.gov/Stem

Vasquez, A. (2015). STEM-Beyond the acronym. Educational Leadership, 72(4), 10-15. Retrieved from http://www.ascd.org/publications/educational-leadership

Wells, J. (2013). Integrative STEM education at Virginia Tech: Graduate preparation for tomorrow's leaders. Technology and Engineering Teacher, 72(5), 28-35. Retrieved from https://www.iteea.org

Yin, R. (2014). Case study research: Design and methods (5th ed.). Thousand Oaks, CA: Sage Publications Inc. 
Table 1

Interview Question Alignment to Research Questions

Interview questions $\quad$ Research question

- Based on your training, describe what STEM looks like in your classroom.

- Based on your training, what do you think STEM should look like in your classroom?

- What do you need to make that change happen?

- What kind of professional development have you participated in regarding STEM?

- What skills or talents do you believe an elementary teacher must have to successfully teach STEM?

- What have you experienced that either helped you develop those skills or prevented you from developing those skills?

- What kind of professional development opportunities would you like to have regarding STEM?

What are the experiences of fifth-grade science teachers regarding STEM-focused professional development?

- What professional development opportunities do you feel would best help teachers to develop the skills or talents you discussed?

Table 2

Participating School Descriptors

\begin{tabular}{|c|c|c|}
\hline School & Income & STEM program \\
\hline School A* & Low & Established \\
\hline School B & Low & Established \\
\hline School C & High & New \\
\hline School D & High & Established \\
\hline School E & High & New \\
\hline School F* & Low & New \\
\hline
\end{tabular}

*School on the cusp of being Title I. Although not Title I at the time of the study, school has met Title I criteria for the 2018-2019 school year. Therefore, the school was coded as low-income.

Table 3

Participant Descriptors

\begin{tabular}{lccl}
\hline Participant Pseudonym & Years teaching & School & Avg. self-efficacy rating \\
\hline Sam & 2 & A & 4.2 moderate \\
Lisa & 10 & B & 4.3 moderate \\
Pam & 20 & C & 4.6 high \\
Mandy & 22 & D & 4.6 high \\
Sandy & 2 & C & 3.6 low \\
Amy & 6 & E & 4.3 moderate \\
Frank & 3 & F & 3.8 low \\
Audrey & 7 & A & 4.0 moderate \\
Sean & 11 & B & 4.4 moderate \\
Brit & 3 & E & 3.7 low \\
Amber & 15 & F & 4.5 high \\
Lacey & 12 & F & 4.3 moderate \\
Mark & 24 & D & 4.7 high \\
Jean & 4 & B & 4.1 moderate \\
\hline
\end{tabular}


Table 4

Frequency with Which Students Engage in Activities during STEM Instruction

\begin{tabular}{|c|c|c|c|c|c|}
\hline \multirow[b]{2}{*}{ Activity } & \multicolumn{5}{|c|}{$f \%$} \\
\hline & Never & Occasionally & $\begin{array}{l}\text { About half } \\
\text { the time }\end{array}$ & Usually & $\begin{array}{l}\text { Every } \\
\text { time }\end{array}$ \\
\hline $\begin{array}{l}\text { Develop problem-solving skills through } \\
\text { investigations }\end{array}$ & 0.0 & 16.7 & 33.3 & 50.0 & 0.0 \\
\hline Work in small groups & 0.0 & 0.0 & 0.0 & 66.7 & 33.3 \\
\hline Make predictions that can be tested & 0.0 & $16 / 7$ & 16.7 & 33.3 & 33.3 \\
\hline Make careful observations or measurements & 0.0 & 16.7 & 0.0 & 50.0 & 33.3 \\
\hline Use tools to gather data & 0.0 & 0.0 & 16.7 & 50.0 & 33.3 \\
\hline Recognize patterns in data & 0.0 & 33.3 & 0.0 & 33.3 & 33.3 \\
\hline $\begin{array}{l}\text { Create reasonable explanations of results of } \\
\text { an experiment or investigation }\end{array}$ & 0.0 & 16.7 & 0.0 & 50.0 & 33.3 \\
\hline $\begin{array}{l}\text { Choose the most appropriate methods to } \\
\text { express results }\end{array}$ & 0.0 & 33.3 & 0.0 & 50.0 & 16.7 \\
\hline Complete activities with a real-world context & 0.0 & 0.0 & 16.7 & 83.3 & 0.0 \\
\hline Engage in content-driven dialogue & 0.0 & 0.0 & 0.0 & 66.7 & 33.3 \\
\hline Reason abstractly & 0.0 & 33.3 & 0.0 & 50.0 & 16.7 \\
\hline Reason quantitatively & 0.0 & 33.3 & 0.0 & 50.0 & 16.7 \\
\hline Critique the reasoning of others & 0.0 & 16.7 & 0.0 & 83.3 & 0.0 \\
\hline $\begin{array}{l}\text { Learn about careers related to the } \\
\text { instructional content }\end{array}$ & 0.0 & 33.3 & 16.7 & 50.0 & 0.0 \\
\hline
\end{tabular}

Table 5

Established Themes by Research Question

\begin{tabular}{ll}
\multicolumn{1}{c}{ Research question } & \multicolumn{1}{c}{ Themes } \\
\hline What are the experiences of fifth-grade science teachers regarding STEM-focused & $\bullet$ Self-directed \\
professional development? & $\bullet$ Limited \\
How do these experiences affect fifth-grade science teachers' self-efficacy in & Creativity \\
implementing integrated STEM education? & \\
What types of professional development experiences do fifth-grade science & Personalized \\
teachers feel best support them in implementing integrated STEM education? & \\
\hline
\end{tabular}

